\title{
GASTROPROTECTIVE EFFECT OF AVENA SATIVA (OAT) SEED GRAINS AGAINST GASTRIC ULCER INDUCED BY INDOMETHACIN IN HEALTHY ADULT MALE ALBINO RABBITS
}

\author{
Anila Kanwal' ${ }^{1}$, Bilal Aslam ${ }^{1}$, Atifa Mushtaq ${ }^{2}$, Hira Anwar ${ }^{1}$, Hafiz Mahboob Ahmed ${ }^{1}$ \\ ${ }^{1}$ Institute of Pharmacy, Physiology and Pharmacology, University of Agriculture Faisalabad, Faisalabad, Pakistan \\ ${ }^{2}$ National Institute of Health, Islamabad, Pakistan \\ *Corresponding Author Email: emankanwal13@yahoo.com
}

This is an open access article distributed under the Creative Commons Attribution License, which permits unrestricted use, distribution, and reproduction in any medium, provided the original work is properly cited.

\section{ARTICLE DETAILS}

\section{Article History:}

Received 12 November 2017 Accepted 12 December 2017 Available online 1 January 2018

\section{ABSTRACT}

Avena sativa which is commonly known as oat has beneficial effects against various diseases especially cancer, bowel syndrome, diabetes, cardiovascular disease and obesity. Gastro protective effect of seed grains of Avena sativa in indomethacin induced ulcer in healthy male adult albino rabbits were evaluated in present study. A total of thirty-six rabbits were divided into six equal groups. Group 1 would be served as control group on routine diet. Indomethacin (indocin) $20 \mathrm{mg} / \mathrm{kg}$ was given to $2^{\text {nd }}$ group to induce ulcer, $3^{\text {rd }}$ group was served by synthetic antiulcer drug Zantac (ranitidine) at the dose of $10 \mathrm{mg} / \mathrm{kg}$ orally while group 4, 5 and 6 were given three different doses of Avena sativa seed powders $250 \mathrm{mg} / \mathrm{kg}, 500 \mathrm{mg} / \mathrm{kg}$ and $750 \mathrm{mg} / \mathrm{kg}$ respectively for 14 days. At the end of experiment rabbits were sacrificed to collect gastric contents for the estimation of total acid output. The blood sample was collected at 0 and 14 days. Antiulcer activity of this plant was analyzed by measuring different parameters like pH, gastric volume, acid output and ulcer index. Result showed that Avena sativa at dose of $750 \mathrm{mg} / \mathrm{kg}$ reduced the values of total oxidant status (TOS), malondialdehyde and increased the total antioxidant capacity and catalase activity and these results were compared with standard drug. From these results it was concluded that Avena sativa has strongest antioxidant potential.

\section{KEYWORDS}

Avena sativa, avenanthramides, Gastroprotective, antioxidant, Indomethacin, COX- inhibitors, ranitidine, gastric ulcer.

\section{INTRODUCTION}

Gastric ulcer is a lesion in the normal mucosal layer of the stomach that extends through the muscular is mucosa into sub mucosa or deeper [1]. It is a common disease that affects $10 \%$ of population. Approximately 500,000 ulcerated patients are diagnosed in the United States each year. Mostly middle-aged people are affected by peptic ulcer disease, but 70 percent of patients are between the ages of 25 and 64 years. Life time occurrence is just about $11-14 \%$ for men and $8-11 \%$ for women [2]. Ulcer is generally caused by disturbance in the balance between destructive (acid/pepsin secretion and Helicobacter pylori infection) and shielding factors (mucosal barrier, mucus secretion, prostaglandins) in the stomach [3]. Some physical, chemical and microbial agents which are involved in ulceration of gastrointestinal tract are stress, smoking, alcohol ingestion, non-steroidal anti-inflammatory drugs and Helicobacter pylori [4].

NSAIDs are the most prescribed drugs which are an important cause of gastric damage. These are most frequently used among women. The concurrent use of these drugs injures the GIT tract because of their acidic properties. NSAIDs also show systemic effects by inhibiting cyclooxegenase. It is an enzyme which is involved in biosynthesis of prostaglandins. Prostaglandin which is responsible for the maintenance of gastric mucous is blocked by COX-1 inhibitors such as aspirin, indomethacin, ibuprofen and ketoprofen [5]. Gastric/peptic ulcers can be prevented by lowering the gastric acid production and by increasing the protection of stomach mucosal wall. Ulcer therapy has progressed from vagotomy to histamine $\mathrm{H}_{2}$ receptor antagonists, anticholinergic drugs, antacids and proton pump inhibitors. $\mathrm{H}_{2}$ receptor antagonist is the major class of synthetic drug for the management of peptic ulcer [6].

In connection with severe side effects of antiulcer drugs, focus is now diverted towards the use of herbal medicines against gastric ulcer [7]. Avena sativa (oat) is the gastro protective plant which belongs to the family graminaceae. Its phytochemical analysis showed that it has highest lipid fractions as compared to any other feeding crops. Avenanthramides are polyphenols which are present only in oat seeds. It shows higher antioxidant capacity as compared to any other cereal components [8].

Avena sativa can improve the blood pressure when it is used with vitamin $\mathrm{C}$ due to its cholesterol lowering effect. A. sativa reduces both total cholesterol as well as low density lipoprotein. It reduces blood pressure and is used to treat stress, excitation, tension and anxiety [9]. It is indicated in cardiovascular diseases, metabolic diseases such as diabetes and improving endothelial function but scientific in formations regarding its ulcer protective activity is not available [10]. Keeping in view the medicinal value of its components, the gastro protective activity of Avena sativa was evaluated in experimentally induced ulcerated albino rabbits. The main objective of study was to evaluate the antioxidant and gastro protective efficacy of Avena sativa seed powder in response to indomethacin induced gastric toxicity.

\section{MATERIAL AND METHODS}

\subsection{Animals}

36 male adult albino rabbits weighing $1.5-2 \mathrm{~kg}$ were purchased from NIH (National Institute of Health) and housed at experimental animal room, Department of Physiology and Pharmacology, University of Agriculture, Faisalabad, Pakistan. Rabbits were kept at room temperature $\left(22 \pm 2^{\circ} \mathrm{C}\right)$. Rabbits of different groups were placed in different cages to facilitate accurate evaluation. Prior to the experimentation, rabbits were acclimatized for one week and provided with standard feed and water ad libidum. The experiment was conducted with prior approval by the Directorate of Research and Advanced studies and with the consent of the society of Ethics of Animals, University of Agriculture, and Faisalabad Pakistan.

\section{$2.2 \quad$ Feed and Drugs}

The rabbits were provided normal routine feed till the completion of experiment. The feed was made available twice a day, in morning and evening. However, drinking water was available throughout 24 hours 
Indocin ${ }^{\circledR}$ (indomethacin) was given at the dose rate of $20 \mathrm{mg} / \mathrm{kg}$ for induction of ulcer [3]. The synthetic antiulcer drug zantac $₫$ was purchased from GlaxoSmithKline Laboratories Limited Karachi, Pakistan. Drug was administered to the adult rabbits at a dose rate of $10 \mathrm{mg} / \mathrm{kg}$ orally once in a day for 14 days [11].

\subsection{Plant Material}

Seed grains of Avena sativa were purchased from the local herbal dealers of Faisalabad. The plant material was authenticated and compared with its

standard in the herbarium maintained by Department of Botany, University of Agriculture Faisalabad. The samples were preserved in the pharmacology laboratory of department of physiology and pharmacology, University of agriculture Faisalabad. These seed grains were powdered with the help of a special electrical grinder. This process was done with precaution that the temperature did not raise up to $40^{\circ} \mathrm{C}$. This powder was passed through mesh sieve no. 200 and then stored in airtight container for further experimental use.

\subsection{Treatment Protocol}

Table1: Feeding and drug administration schedule in rabbits during the experimental period of 0-14 days

\begin{tabular}{|l|l|}
\hline Group1: Untreated Control on normal routine diet. & Routine diet for 0-14 days \\
\hline Group 2: Untreated control on indomethacin (indocin) 20 mg/kg & Rabbits received routine diet + indomethacin for 0-14 days. \\
\hline $\begin{array}{l}\text { Group 3: Treated control on synthetic antiulcer drug Zantac } \\
\text { (ranitidine) }\end{array}$ & Rabbits received routine diet + ranitidine and indomethacin for 0-14 days \\
\hline Group 4: Treated on Avena sativa seed grain powder $250 \mathrm{mg} / \mathrm{kg}$ orally & Rabbits received routine diet + indomethacin+ Avena sativa (oat) seed grain powder for 0-14 days. \\
\hline Group 5: Treated on Avena sativa seed grain powder $500 \mathrm{mg} / \mathrm{kg}$ orally & Rabbits received routine diet + indomethacin+ Avena sativa (oat) seed grain powder for 0-14 days. \\
\hline Group 6: Treated on Avena sativa (oat) seed grain powder $750 \mathrm{mg} / \mathrm{kg}$ & Rabbits received routine diet + indomethacin and Avena sativa seed grain powder for 0-14 days. \\
\hline
\end{tabular}

\subsection{Surgical Procedures}

The animals were fasted for at least 6 hours before the surgical procedure. On the 14 days of experiment these animals were sacrificed. The rabbits were slaughtered one by one, blood samples were collected and then the stomach of the animal was separated with the help of sharp scissors. The stomach was cut along the greater curvature and the contents were collected into small tubes. These gastric contents were then centrifuged at $2000 \mathrm{rpm}$ for 5 minutes. The supernatant was separated, and its volume was expressed as $\mathrm{ml} / 100 \mathrm{~g}$ body weight. This supernatant was used for the estimation of various biochemical parameters.

\subsection{Blood Sampling}

Blood samples were collected in gel tubes. These were then centrifuged, and serum was separated. It was collected in small clean bottles and was stored at refrigeration temperature. It was used for the evaluation of different antioxidant parameters.

\subsection{Procedure for Antiulcer Evaluation Studies}

\subsubsection{Determination of $\mathrm{pH}$ and gastric volume}

The $\mathrm{pH}$ of the supernatant obtained was determined with the help of $\mathrm{pH}$ meter. The gastric volume of supernatant obtained was measured precisely by using the micro pipette.

\subsubsection{Acid Output}

The acid output was calculated by titrating the supernatant fluid with $0.05 \mathrm{~N} \mathrm{NaOH}$. Acidity was expressed as $\mathrm{mEq} / \mathrm{L}$ per 100 gram of body weight [12].

\section{Acidity $=\underline{\text { Volume of } \mathrm{NaOH} \times \text { Normality } \times 100 \mathrm{mEq} / \mathrm{l} / 100 \mathrm{~g}}$}

\subsubsection{Ulcer Index Calculations}

The number of ulcers was noted, and the severity was determined with the following scores: Ulcer index will also be determined by following formula: Ulcer index (UI) was calculated using the formula [13]. UI = US + UN + UP $\times 10^{-1}$, Ulcers were given scores based on their intensity as follows: $0=$ normal stomach, $0.5=$ red coloration, $1=$ spot ulcer, $1.5=$ hemorrhagic streak, 2 = ulcers, 3 = perforation. The percentage of ulcer protection will be determined as follows: [14].

Curative Ratio: The curative ratio from the ulcer was calculated for the treated groups by using the following equation. Percentage protection from ulcers $=$ CUI-TUI $/$ CUI

\section{Biochemical Examination Malondialdehyde/MDA (nmol/L):} Malondialdehyde (MDA) was calculated [15].

Catalase ( $k \mathbf{H} / \mathbf{L})$ : Enzymatic activity of enzyme catalase was measured [16].

Total oxidant status/TOS ( $\mu \mathrm{mol} / \mathrm{L})$ : The total oxidant status in serum was measured [17].

Total Antioxidant capacity/TAC (mmol/L): The total antioxidant capacity in serum samples was measured [18].

\subsection{Statistical Analysis}

The values were expressed as mean \pm SE. Statistical analysis was performed by one-way analysis of variance (ANOVA) and statistical differences among different treatment groups were determined by Duncan's Multiple Range test at $5 \%$ level of significance [19].

\section{RESULTS}

\subsection{Antiulcer Evaluation Parameters}

Results showed that Mean \pm SE values of ulcer scores were increased significantly $(\mathrm{P}<0.01)$ in rabbits treated with indocin $(2.75 \pm 0.21)$. Ranitidine reduced ulcer scores $(0.5 \pm 0.13)$ in comparison with indocin treated rabbits $(2.75 \pm 0.21)$. A sativa at dose rate of 250,500 and 700 $\mathrm{mg} / \mathrm{kg}$ significantly reduced ulcer scores $(2.08 \pm 0.23),(1.58 \pm 0.20)$ and $(0.67 \pm 0.10)$ respectively. It was also observed that $\mathrm{pH}$ was decreased significantly in indocin treated rabbits $(0.99 \pm 0.12)$. Ranitidine enhanced $\mathrm{pH}(4.74 \pm 0.32)$ of gastric mucosa. Seed powder of A. sativa at dose rate of 250,500 and $700 \mathrm{mg} / \mathrm{kg}$ significantly enhanced the $\mathrm{pH}(1.77 \pm 0.21)$, $(2.77 \pm 0.28)$ and $(4.58 \pm 0.34)$ respectively. Results also demonstrated that gastric volume was increased significantly in indocin treated rabbits (19.0 \pm 0.33$)$. Ranitidine reduced gastric volume $(9.85 \pm 0.37)$. Seed powder of A. sativa at dose rate of 250,500 and $700 \mathrm{mg} / \mathrm{kg}$ significantly decreased gastric volume $(16.4 \pm 0.31),(13.6 \pm 0.23)$ and $(11.3 \pm 0.18)$ respectively (Table. 2).

Table 2: Mean \pm SE values of ulcer scores, $\mathrm{pH}$ and gastric volume after the 14 days of treatment with per oral drugs and Avena sativa seed powder in rabbits.

\begin{tabular}{|c|c|c|c|}
\hline Group & Dose & Ulcer Score & Gastric Volume \\
\hline Control & Routine feed & 0 & $10.6 \pm 0.31$ \\
\hline Indomethacin & $20 \mathrm{mg} / \mathrm{kg}$ & $2.75 \pm 0.21$ & $13.95 \pm 0.33$ \\
\hline Ranitidine & $10 \mathrm{mg} / \mathrm{kg}$ & $0.5 \pm 0.13$ & $0.99 \pm 0.12$ \\
\hline A.sativa & $250 \mathrm{mg} / \mathrm{kg}$ & $2.08 \pm 0.23$ & $4.74 \pm 0.32$ \\
\hline A.sativa & $500 \mathrm{mg} / \mathrm{kg}$ & $1.58 \pm 0.20$ & $1.77 \pm 0.21$ \\
\hline A.sativa & $750 \mathrm{mg} / \mathrm{kg}$ & $0.67 \pm 0.10$ & $2.77 \pm 0.28$ \\
\hline
\end{tabular}


Results demonstrated that total acid output was increased significantly $(\mathrm{P}<0.01)$ in indocin treated rabbits $(26.5 \pm 0.39)$. Ranitidine reduced total acid output $(17.1 \pm 0.28)$ in comparison with indocin treated rabbits $(26.5 \pm 0.39)$. Seed powder of $A$. sativa at dose rate of 250,500 and $700 \mathrm{mg} / \mathrm{kg}$ significantly reduced total acid output (24.1 \pm 0.34$),(20.2 \pm 0.39)$ and $(15.8 \pm 1.52)$ respectively. It was also noted that ulcer index was increased significantly $(\mathrm{P}<0.01)$ in indocin treated rabbits $(13.09 \pm 0.006)$. Ranitidine reduced ulcer index $(2.78 \pm 0.006)$ in comparison with indocin treated rabbits
(13.09 \pm 0.006$)$. Seed powder of A. sativa at dose rate of 250, 500 and $700 \mathrm{mg} / \mathrm{kg}$ significantly reduced ulcer index $(6.75 \pm 0.009)$, $(4.40 \pm 0.007)$ and $(3.18 \pm 0.003)$ respectively. Curative ratio was calculated for treated groups which determined that three doses of seed powder of A. sativa 250, 500 and $700 \mathrm{mg} / \mathrm{kg}$ showed $48.43 \%$, $66.38 \%$ and $75.7 \%$ gastric protection respectively. Ranitidine was used as synthetic antiulcer drug which showed $79.06 \%$ protection (Table. 3).

Table 3: Mean \pm SE values of acid output, ulcer index and curative ratio after the 14 days of treatment with per oral drugs and Avena sativa seed powder in rabbits.

\begin{tabular}{|c|c|c|c|}
\hline Group & Dose & Acid output & Ulcer index \\
\hline Control & Routine feed & $14.1 \pm 0.25$ & 0 \\
\hline Indomethacin & $20 \mathrm{mg} / \mathrm{kg}$ & $26.5 \pm 0.39$ & $13.09 \pm 0.006$ \\
\hline Ranitidine & $10 \mathrm{mg} / \mathrm{kg}$ & $17.1 \pm 0.28$ & 0 \\
\hline A.sativa & $250 \mathrm{mg} / \mathrm{kg}$ & $24.1 \pm 0.34$ & 0 \\
\hline A.sativa & $500 \mathrm{mg} / \mathrm{kg}$ & $20.2 \pm 0.39$ & 0.006 \\
\hline A.sativa & $750 \mathrm{mg} / \mathrm{kg}$ & $15.8 \pm 1.52$ & $4.40 \pm 0.009$ \\
\hline
\end{tabular}

\subsection{Biochemical Examination}

Oxidative health biomarkers were also measured in the current study. Results suggested that indocin significantly enhanced the TOS $(4.51 \pm 0.07)$ and MDA (9.41 \pm 0.36$)$ levels while it caused a significant reduction in TAC $(0.89 \pm 0.09)$ and catalase $(2.93 \pm 0.29)$ activity. However, administration of ranitidine significantly enhanced the TAC $(1.5 \pm 0.023)$ and catalase
$(8.07 \pm 0.26)$ activity and caused a significant reduction in TOS $(2.69 \pm 0.16)$ and MDA (4.74 \pm 0.30 ) levels. Seed powder of A. sativa 250, 500 and 700 $\mathrm{mg} / \mathrm{kg}$ significantly increased the TAC $(1.13 \pm 0.04,1.22 \pm 0.06,1.47 \pm 0.04)$ and catalase $(4.32 \pm 0.35,5.95 \pm 0.24,7.49 \pm 0.29)$ activity respectively hence significantly reduced the levels of TOS $(3.90 \pm 0.15),(3.34 \pm 0.03)$ $(2.64 \pm 0.14)$ and MDA $(7.64 \pm 0.16),(6.08 \pm 0.26),(5.05 \pm 0.17)$ respectively (Table. 4).

Table 4: Mean \pm SE values of TOS, TAC, MDA and Catalase after the 14 days of treatment with per oral drugs and Avena sativa seed powder in rabbits.

\begin{tabular}{|c|c|c|c|c|}
\hline Group & Dose & TOS & TAC & MDA \\
\hline Control & Routine feed & $3.34 \pm 0.44$ & $1.61 \pm 0.02$ & $3.78 \pm 0.15$ \\
\hline Indomethacin & $20 \mathrm{mg} / \mathrm{kg}$ & $8.68 \pm 1.03$ & $0.89 \pm 0.09$ & $9.41 \pm 0.36$ \\
\hline Ranitidine & $10 \mathrm{mg} / \mathrm{kg}$ & $4.60 \pm 0.75$ & $1.5 \pm 0.023$ & $4.74 \pm 0.30$ \\
\hline A.sativa & $250 \mathrm{mg} / \mathrm{kg}$ & $7.70 \pm 0.82$ & $1.13 \pm 0.04$ & $2.93 \pm 0.71$ \\
\hline A.sativa & $500 \mathrm{mg} / \mathrm{kg}$ & $6.58 \pm 0.77$ & $1.22 \pm 0.06$ & $7.64 \pm 0.16$ \\
\hline A.sativa & $750 \mathrm{mg} / \mathrm{kg}$ & $4.92 \pm 0.63$ & $1.47 \pm 0.04$ & $6.08 \pm 0.26$ \\
\hline
\end{tabular}

\section{DISCUSSION}

Peptic ulcer is the most common gastrointestinal disorder which encompasses gastric and duodenal ulcer [20]. In this disease, mucosal defensive mechanism (mucus secretion, mucosal barrier, cell regeneration, blood flow and prostaglandins) moves towards the mucosal offensive mechanism. Some physical, chemical and microbial agents which are involved in ulceration of gastrointestinal tract are stress, smoking, alcohol ingestion, non-steroidal anti-inflammatory drugs and Helicobacter pylori [4]. Synthetic drugs (antacids, proton pump inhibitors, and anticholinergic and histamine receptor blockers) are used for the treatment of gastric ulcer. Prolong use of these drugs produce adverse effects and develop the tolerance which limits the use of these drugs [21]. For these reasons, the search for new drugs is very important and medicinal plants play a key role in these studies. Many extracts and isolated compounds from plants have shown promising results in the treatment and prevention of gastric ulcers [22].

One of the most important NSAIDs is indomethacin which is used in various pathological diseases like arthritis and inflammation. It induces ulcer by inhibiting the enzyme cyclooxygenase which has two (COX-1 and COX-2) isoforms [23]. Indomethacin reduces the nitric oxide biosynthesis in gastric mucosa by reducing the level of eNOS which in turn damages the mucosal wall [24]

Butanolic fraction of $A$. sativa showed most potent activity through inhibition of COX mediated generation of arachidonic acid metabolites [25]. Butanolic fraction also inhibits LP-1 and 12-HETE metabolites of LOX. It is reported that cardiovascular and anti-inflammatory activities of A. sativa are mediated through inhibition of LOX and COX pathways. This new information provides a theoretical basis for development of new antiinflammatory approaches targeted to COX and LOX enzyme activity [26].

It has been studied that oat contains polyphenols which are involved in generation of eNOS and improve the endothelial functions [27]. Saponins are the active constituent of most of the plants. Their gastric protective activity in several ulcer models is reported. Their activity against ulceration is not only due to stimulation of mucous membrane defensive factors but also due to inhibition of gastric acid secretion through inhibition of $\mathrm{PGF}_{2 \alpha}$ and synthesis of protective mucous layer on gastric mucosa. The activity of the $A$. sativa against gastric ulcer could thus be attributed to the occurrence of saponins [3].
Alkaloids (secondary metabolites) are present in $20 \%$ of plant. It has been reported in many biological activities like antitumor, diuretic, antiviral, antimicrobial and anti-inflammatory. Alkaloid possess antiulcer activity by increasing the $\mathrm{pH}$ and luminal gastric output of basal bicarbonate [1]

Ranitidine is a synthetic drug which reduces the gastric content by antagonizing the binding of histamine to $\mathrm{H}_{2}$ receptor on parietal cells [28] It reduces the concentration of hydrogen ions in the gastric juice. But longterm use of histamine receptor antagonists may cause gynecomastia in males and galactorrhea in females, arrhythmia, confusion, cardiac arrest, headache and bowel upset [29]. Avena sativa is distinct among the cereal grain due its multifunctional nutrition values. It was used as medicinal plant because of its unique profile [30]. Oat contains avenanthramides having antihistaminic property, so it can also reduce the concentration of $\mathrm{H}^{+}$in the gastric juice and increase the $\mathrm{pH}$ of gastric contents [31].

In this study we have evaluated the ulcer protective activity of Avena sativa seed grains. Its powder was used in male albino rabbits at graded doses. Its efficacy against ulcer was assessed by measuring the ulcer scores, ulcer index, acid output, $\mathrm{pH}$, curative ratio and gastric secretions. Results of these parameters showed that group which was given indomethacin has highest value of ulcer index, ulcer scores, acid output, gastric volume and lower value of $\mathrm{pH}$. But the group which was served indomethacin along with ranitidine showed significant lower values of ulcer index, gastric volume and also increased the value of $\mathrm{pH}$. Similar results were exhibited by the group which was served with indomethacin and Avena sativa at dose of $750 \mathrm{mg} / \mathrm{kg}$. Other factor which is responsible for induction of ulcer is generation of reactive oxygen species. These species are produced in response to disturbance in oxidant and antioxidant cellular process [3]. MDA is an organic compound that is used as a biomarker to determine the level of oxidative stress in an organism. Increased levels of MDA increase the levels of lipid per oxidation process [32].

Results of these analysis showed that groups which were served with ranitidine and Avena sativa at dose of $750 \mathrm{mg} / \mathrm{kg}$ possess reduced value of MDA. Avena sativa showed strongest antioxidant potential because it contained several constituents with antioxidant activity like vitamin E, flavonoids, tocopherols, sterols, vanillic acid, phenolic compounds and phytic acid. Simple polyphenolic and phenolic acids which are present in oats exhibit potent antioxidant activity both in plants and in those animals that consume those [33]. Oat possesses health associated benefits due to its antioxidant ability [34]. 
A group of amides and avenanthramides has been found in oats. Oat grain extract contains more than 25 different types of avenanthramides. It has 10-30 times greater antioxidant capacity as compared to other phenolic compounds which are present in oats like caffeic acid and vanillin [35]. A monitor of immune response to infection is the suppression of NF-k $\beta$. It acts as a key in restraining the propagation of cancer cells and decreasing the level of inflammation [36]. Avenanthramides which are active constituents of oat inhibit NF-k $\beta$ activation [37]. They play an important role in reducing the proliferation and inflammation in ulcerated area. This activity increases the synthesis of endogenous antioxidant enzymes like catalase, glutathione peroxidase, superoxide dismutase and reduces the levels of MDA and TOS in the serum

\section{CONCLUSION}

The present study provides preliminary data that powder of seed grains of Avena sativa possess gastroprotective activity against gastric mucosal damage induced by indomethacin. It can be concluded that the ingredients of Avena sativa can be regarded as the contributing factors in the treatment of peptic ulcer disease. The advanced research may discover its exact mechanism in PUD. However, more research work is needed to find out the active principle in this plant extract so that it can be purified, characterized and commercialized for the treatment of gastric ulcer. Enormous numbers of studies are to be done to bring its products to commercial exploitation.

\section{REFERENCES}

[1] Omoja, V.U., Ihedioha, T.E., Eke, G.I., Peter-Ajuzie, I.K., Okezie, S.E. 2014. Evaluation of the acute toxicity, phytochemical constituents and anti - ulcer properties of methanolic leaf extract of Annona muricata in mice. Journal of Intercultural Ethnopharmacology, 3, 37-43.

[2] Kumar, M.S., Ghosh, A., Kumar, Y.A., Dileep, K. and Kumar, S.A. 2014. Kamadugha rasa an effective ayurvedic formulation for peptic ulcer: a review. Global Journal of Research on Medicinal plants \& Indigenous medicine, 3, 24-32.

[3] Choudhary, M., Kumar, V., Singh, S. 2014. Gastric anti secretory and cytoprotective effects of hydro alcoholic extracts of Plumeria alba Linn. leaves in rats. Journal of Integrative Medicine, 12, 42-51.

[4] Tend, J.A., Eze, E.D., Tend, Y.A., Onaadepo, O., Shaibu, A. 2013. Antiulcerogenic activity of Guava (Psidium guajava) leaves extract in rats. Ann. Exp. Biol., 1, 6-9.

[5] Yin, H., Pan, X., Song, Z., Wang, S., Yang, L., Sun, G. 2014. Protective effect of wheat peptides against small intestinal damage induced by nonsteroidal anti-inflammatory drugs in rats. Journal of Integrative Agriculture, 1, 564-574.

[6] Awaad, A.S., El-Meligy, R.M., Soliman, G.A. 2013. Natural products in treatment of ulcerative colitis and peptic ulcer. Journal of Saudi Chemical Society, $17,101-124$.

[7] Koehn, F.E., Carter, G.T. 2005. The evolving role of natural products in drug discovery. Nature Reviews Drug Discovery, 4, 206-220.

[8] Chatuevedi, N., Yadav, S., Shukla, K. 2011. Diversified therapeutic potential of Avena sativa: an exhaustive review. Asian Journal of Plant Science and Research, 1, 103-114.

[9] Schellekens, C., Moccetti, T.P., Wullschleger, C., Heyne, A. 2009. An extract from wild green oat improves rat behavior. Phytotherapy Research, 23, 1371-1377.

[10] Feng, B., Ma, L., Yao, J., Fang, Y., Mei, Y., Wei, S. 2013. Protective effect of oat bran extracts on human dermal fibroblast injury induced by hydrogen peroxide. Journal of Zhejiang University Science B, 14, 97-105.

[11] SriKumar, P.P., Pardhasaradhi, P. 2013. Preliminary phytochemical investigation and anti- ulcer activity of aerial parts of Ruellia tuberosa $L$ (Acanthaceae) in male wistar rats. International journal of pharmaceutical and biomedical research, 4, 145-148.

[12] Gautama, R., Sharma, S.C. 2012. Antiulcer activity of Punica granatum Linn. In diabetic rats. International Journal of Pharmacy and Pharmaceutical Sciences, 4, 459-461.

[13] Vogel, H.G. 2002. Drug discovery and evaluation, pharmacological assay. $2^{\text {nd }}$ Ed. Springer, Germany, 759-767.
[14] Sharma, R.K., Mandal, S., Rajani, G.P., Gupta, N., Srivastava, N. 2011 Antiulcer and anti-inflammatory activity of fresh leave extracts of Polyalthia longifolia in rats. International Journal of Drug Development and Research, 3, 351-359.

[15] Ohkawa, H., Ohishi, N., Yag, K. 1979. Assay for lipid peroxides in animal tissue by thiobarbituric acid reaction. Anol. Biochem., 95, 351-358.

[16] Goth, L. 1991. A simple method for determination of serum catalase and reversion of reference range. Clinica Chimica Acta, 2, 143-145.

[17] Erel, 0. 2005. A new automated colorimetric method for measuring total oxidant status. Clinical Biochemistry, 38, 1103-1111.

[18] Erel, 0. 2004. A novel automated direct measurement method for total antioxidant capacity using a new generation, more stable ABTS radical cation. Clinical Biochemistry, 37, 277-285.

[19] Steel, R.G.D., Torrie, J.H., Dickey, D.A. 1997. Principles and procedures of statistics. $3^{\text {rd }}$ Ed. McGraw Hill, New York, USA.

[20] Barua, N., Das, M., Das, S. 2014. The effect of Musa sapientum methanolic fruit extract on volume of gastric juice and pepsin activity in aspirin induced peptic ulcers in albino rats. International Journal of Pharmaceutical Sciences and Research, 5, 178-182.

[21] Sheen, E., Triadafilopoulos. 2011. Adverse effects of long-term proton pump inhibitor therapy. Digestive Diseases and Sciences, 56, 931950.

[22] Massignani, J.J., Lemos, M., Maistro, E.L., Schaphauser, H.P., Jorge, R.F., Sousa, J.P., Bastos, J.K., Andrade, S.F.D. 2009. Antiulcerogenic activity of the essential oil of Baccharis dracunculifolia on different experimental models in rats. Phytotherapy Research, 23, 1355-1360.

[23] Augustine, B.B., Pitta, S., Lahkar, M., Dash, S., Samudrala, P.K., Thomas, J.M. 2014. Ulcer protective effect of Leucas aspera in various experimental ulcer models. Asian Pacific Journal of Tropical Disease, 4, 395-402.

[24] Abdullah, I.Z.A., Khattaba, H.A.H., Heebab, G.H. 2011. Gastro protective effect of Cordia myxa L. fruit extract against indomethacininduced gastric ulceration in rats. Life Science Journal, 8, 433-445.

[25] Ahmed, S., Gul, S., Gul, H., Bangash, M.H. 2013. Anti-inflammatory and anti-platelet activities of Avena sativa are mediated through the inhibition of cyclooxygenase and lipoxygenase enzymes. International journal of endorsing health science research, 1, 62-65.

[26] Saeed, S.A., Ahmad, N., Ahmed, S. 2007. Dual inhibition of cyclooxygenase and lipoxygenase by human haptoglobin: its polymorphism and relation to hemoglobin binding. Biochemical and Biophysical Research Communications, 353, 915 - 920.

[27] Nie, L., Wise, M.L., Peterson, D.M., Meydani, M. 2006. Avenanthramide, a polyphenol from oats, inhibits vascular smooth muscle cell proliferation and enhances nitric oxide production. Atherosclerosis, $186,260-266$

[28] Banji, D., Singh, J., Banji, O.J. 2010. Scrutinizing the aqueous extract of leaves of Pedalium murex for the antiulcer activity in rats. Pakistan Journal of Pharmaceutical Sciences, 23, 295-299.

[29] Mahendra, K.B., Naveen, K.H.D., Chakrapani, K., Sowmya, M. 2012 Gastroprotective agents use with nonsteroidal antiinflammatory drugs: an overview. Indian Journal of Pharmacy Practice, 5, 1-20.

[30] Butt, M.S., Nadeem, M.T., Khan, M.K., Shabir, R., Butt, M.S. 2008. Oat: unique among the cereals. European Journal of Nutrition, 47, 68-79.

[31] Kurtz, E.S., Wallo, W. 2007. Colloidal oatmeal: history, chemistry and clinical properties. Journal of Drugs in Dermatology, 6, 167-170.

[32] Abeer, Y.I., Shaffie., N.M. 2013. Protective effect of Solanum indicum var distichum extract on experimentally induced gastric ulcers in rat Global Journal of Pharmacology, 7, 325-332.

[33] Chen, C., Milbury, P.E., Kwak, H., Collins, F.W., Sameul, P., Blumburg, J.B. 2004. Avenanthramides and phenolic acids from oats are bioavailable 
and act synergistically with vitamin C to enhance hamster and human ldl resistance to oxidation. American Society for Nutrition, 22, 1459-1466.

[34] Peterson, D.M., Hahn, M.J., Emmons, C.L. 2002. Oat avenanthramides exhibit antioxidant activities in vitro. Food Chemical, 79, 473-478.

[35] Meydani, M. 2009. Potential health benefits of avenanthramides of oats. Nut. Rev., 67, 731-735.
[36] Baeuerle, P.A., Henkel, T. 1994. Function and activation of Nf-kappa$B$ in the immune-system. Annual Review of Immunology, 12, 141-179.

[37] Guo, W., Wise, M.L., Collins, F.W., Meydani, M. 2008 Avenanthramides, polyphenols fromoats, inhibit IL-1 (beta)-induced NF(kappa) B activation in endothelial cells. Free Radical Biology and Medicine, 44, 415-429. 